11.effects. If, however, two-thirds or more of the organ are taken away the operation is usually fatal. Ponfick has made a similar series of experiments and has come to like conclusions.

Regeneration of liver tissue.-The liver tissue appears to be regenerated by a new formation from the part of the organ which remains. If half the liver of an animal be removed and it be killed at the expiration of two months the liver has regained its ordinary size. From the series of experiments which I have made upon many animals and a study of all the recorded cases of removal of portions of the liver in man I have come to the following conclusions, viz.:1. That the dangers of hæmorrhage after removal of portions of the liver have been much exaggerated. 2. That the best method of controlling and arresting hæmorrhage from liver tissue after it has been incised or torn is by temporary compression of the blood-vessels in the gastrohepatic omentum and then ligature of the divided vessels. 3. That when the liver is the seat of growths such as I have mentioned a surgeon ought to be prepared to carry out an operation for their removal. 4. That the mortality which will result from operations of this kind is not greater than in many of the recognised abdominal operations, such as resection of the intestine.

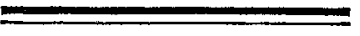

A CASE OF

SCARLET FEVER COMPLICATED WITH ACUTE SUPPURATIVE OTITIS MEDIA AND ACUTE HÆMORRHAGIC SEPTICEMIA TREATED BY ANTISTREPTOCOCCIC SERUM; RECOVERY.

By haROLD LOW, M.A., M.B., B.C. Cantab.

A GIRL, aged six years, was seized on May 12th, 1897, with a severe attack of scarlet fever. The temperature for the first three days ranged between $103^{\circ}$ and $105^{\circ} \mathrm{F}$., except when it was temporarily reduced by tepid sponging. The fances, although considerably swollen, were remarkably free from secretion, the chlorine spray and douche being frequently used. On the fourth day of the rash pain in the left ear was complained of. On the next erening (May 16th) there was slight discharge from the ear. Syringing with boracic acid solution every two hours was ordered. On the 17th there was distinct tenderness over the left mastoid process. The pus came through a large perforation in the membrana tympani and boracic solution used as a nasal douche passed out of the ear. The child was somewhat heary and drowsy and had passed urine involuntarily during sleep. The temperature continued high. On the 18th Mr. Charles Ballance was asked to see the patient with a view to operation. The tenderness over the mastoid still continued, but there was no odema or redness of tissues over it. For the next twenty-four hours the ear was syringed every two hours with carbolic lotion 1 in 40 and hot boracic fomentations were applied. On the 9 th, at 9.30 P.M., as there was no relief, Mr. Ballance operated. The mastoid antrum was opened in the usual way and pus welled ont at the first touch of the gouge. The tympanic cavity itself was carefully avoided. A drainagetube was inserted and the wound was closed. The child bore the operation very well and the temperature fell a degree. On the 21st the child was becoming lethargic and drowsy. She vomited several times. During the day the temperature varied between $100.8^{\circ}$ and $101.8^{\circ}$. On the 22 nd drowsiness was increasing, the tongue was furred, and the abdomen was distended. The patient vomited once. The temperature was still high and the pulse was 130 , regular, bot very weak. On the morning of the $23 \mathrm{rd}$ the skin was jaundiced, the conjunctiva were yellow, and the urine was bile-stained. The abdomen was very distended. Drowsiness was more intense and the child lay perfectly still in a semi-comatose condition. At 10 P.M. the temperature had risen to $103.8^{\circ}$. Mr. Ballance was asked to see the patient and as it was agreed that her condition was due to general septicæmic infection and not to localised intracranial inflammation treatment by anti-streptococcic serum appeared to be the only hope of life. The serum was obtained direct from $\mathrm{Mr}$. Bokenham, who kindly made the first injection of 10 c.c. at 10.30 P.M. On the 24 th, a short time after the injection, the child seemed somewhat brighter and took more notice of things. The tongue was cleaner and of a pinkish hue. The temperature fell to $998^{\circ}$ during the early morning but rose during the day to $103^{\circ} .10$ c.c. of the serum were injected at 4.30 A.M., 11.15 A.M. and 5.30 P.M. whilst at midnight 20 c.c. were given. 3 minims of solution of strychnia with 2 minims of tincture of digitalis were ordered to be administered hypodermically at the same time as each injection of serum. On the 25th during the night the child had a syncopal attack and the temperature fell to $99^{\circ}$. She was distinctly orse in the morning. 10 c.c. of the serum were injected at 6 A.M. At noon the patient was rapidly losing ground; diar$r$ hoa had set in, the pulse was 140, and the respirations were 40. The tongue was furred and the lips were dry and covered with sordes; the abdomen was more distended. 20 c.c. were injected at 6 P.M. and 20 c.c. again at 9 P.M. When seen by Dr. Sharkey ( 9.30 P.M.) the child was lying in a drowsy, almost moribund condition. The palse was very weak (140) and the respirations were 46 . The diarrhcea continued, the motions, consisting of nndigested food, being very offensive.

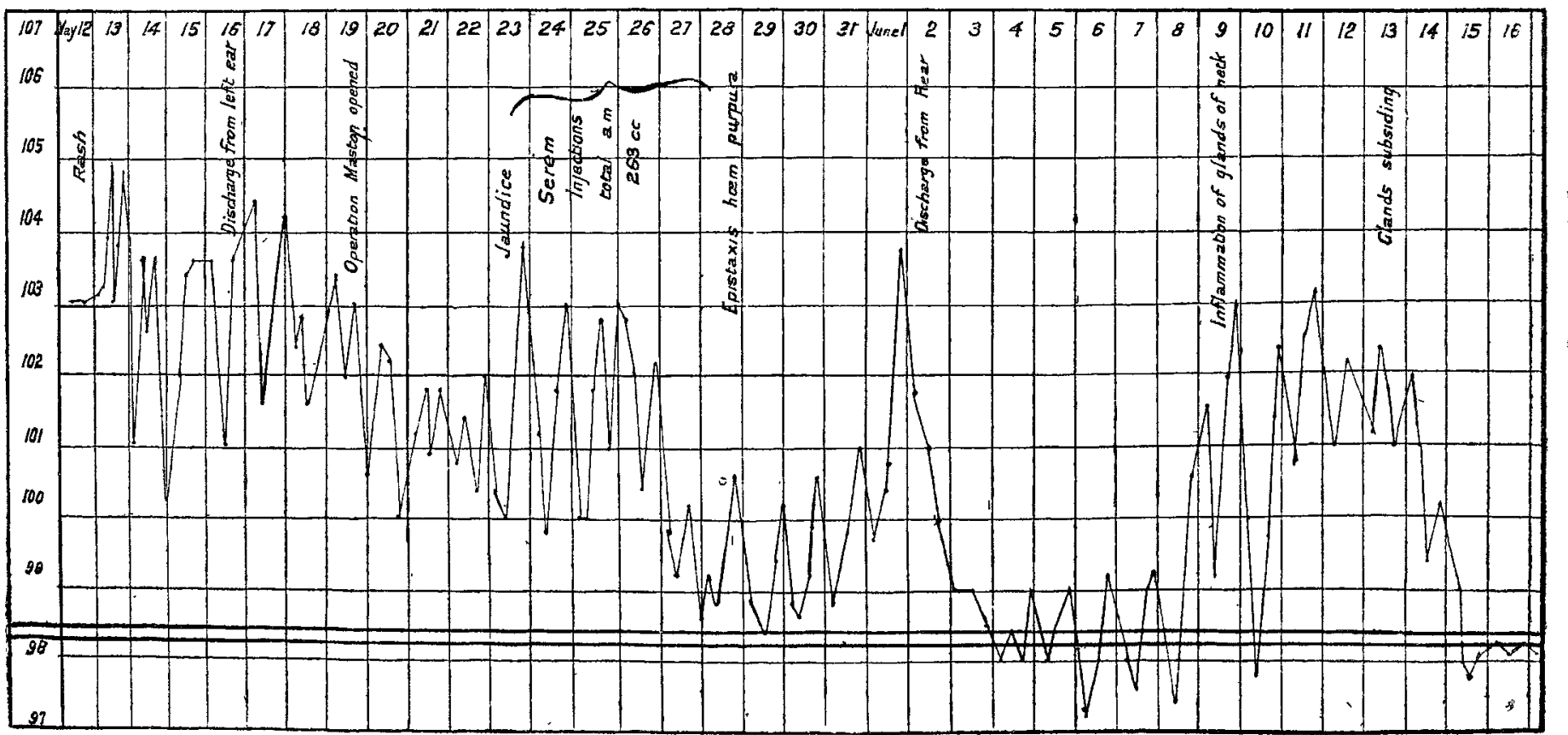

The temperature shows very clearly the various complications of the illness. Firstly, the initial fall on the third day of the rash followed immediately by the rapid rise when the left ear became involved. Secondly, the temporary relief from the operation began to get the better of the disease. preduced by the glandular infiammation. From June 15 th onwards the temperature never rose above normal. 
Dr. Sharkey considered the condition to be extremely grave, bot advised the continuance of the serum treatment and also ordered sulpho-carbolate of sodium, 3 grains by the mouth every four hours. At midnight 10 c.c. were administered. The patient's condition remained unchanged. On the 26 th there was slight improvement. The pulse was less rapid and the respirations were 37 . The lips and tongue were less dry. The motions were slightly bile-stained. The urine was free from bile. By midnight during the last twentyfour hours 67 c.c. of the serum had been injected. On the 27 th improvement continued. The patient had slept for eight and a half hours; her mental condition was much brighter; the abdomen was less distended and the temperature was lower. The diarrhoea was ceasing, the motions being more natural and less offensive. The child' was taking more nourishment. 56 c.c. of the serum had been injected during the twenty-four hours. On the 28th the patient's condition was distinctly better; the temperature had fallen to $99 \cdot 2^{\circ}$; the pulse was 112 , and the respirations were 30 . The diarrhcea had ceased. The patient had passed a good night. On examination of the abdomen there was felt in the right lumbar region, below the liver but distinct from it, a rounded deepseated swelling of the size of a small apple; it was dull on percussion and free from tenderness. At 9.30 A.M. 20 c.c. of the serum were injected. During the morning there had been several attacks of epistaxis and the urine had become bright red. At 130 P.M. the whole body was covered with small purpuric spots, the swelling in the abdomen was larger and evidently contained blood, and the child was very restless but otherwise was no worse. She was given by the mouth 5 minims of tincture of hamamelis and 3 minims of liquor strychnix. On the 29th the general condition was about the same but the purpura was increasing; the whole body was now covered with large subcutaneous braises, especially where the serum and digitalis had been injected. The injections had not been repeated since the previous morning, 263 c.c. of the serum in all having been used. During the afternoon there had been marked improvement mentally, the child playing with her toys. Calx chlorata (10 grains) was ordered every four hours with plenty of fruit. From May 30th to June 2nd the purpura continued, a large mass formed in the right axilla, and the epistaxis at one time became so excessive as to necessitate plugging of the anterior nares, the child in the meantime becoming blanched and very weak. On the morning of June 3 rd the right ear was discharging. There had been a sudden rise of temperature in the night. From June 3 rd to 8 th the purpura gradually dis. appeared and the child slowly improved, the temperature keeping nearly normal. From the $9 \mathrm{kh}$ to the 16th the temperature was again high and there was considerable glandular trouble in the neck. This, however, subsided spontaneously. The urine at the same time contained a large amount of albumin. On the 16th the temperature fell to normal and never again rose and the patient slowly convalesced. The condition now (November, 1897) is satisfac. torg. The discharge from both ears has ceased. The hearing is normal in the right ear, but she can only hear a watch at about three inches with the left.

Report from Mr. BoKENHAM.-A broth culture of the child's blood was taken just before commencing the serum treatment. Streptococcl grew rapidly in the broth. A rabbit was injected with 1 c.c. of the culture. The animal died in forty-eight hours.

Remarks by Mr. BALlaNCE. - This case shows what can be done by perseverence and unremitting attention. The opening of the mastoid antrum was undertaken with the view not only of relieving pain and of giving unhindered exit to pent-up pus, but also in the hope of saving the delicate structures of the tympanum from complete destruction. On May 23rd the child's condition was exceedingly grave. The absence of paresis, optic neuritis, and cerebral vomiting negatived the presence of localised or diffused intra cranial inflammation. Moreover the general septic condition did not seem to depend on infection from the temporal bone which a suitably-planned operation on the lateral sinus and jugular vein might arrest. The high fever, rapid pulse, rapid respiration, jaundice, drowsiness, incontinence of urine, distension of the abdomen, fotid diarrhoea, and later the hæmorrhages made for the diagnosis of general acute scarlatinal septicæmia. This child would certainly have died if anti-streptococcic serum had not been employed and the injections continued even when fe was ebbing away. The serum steadied the temperature, improved the pulse and respiration, cleared the mind, moistened the tongue, and postponed the fatal issue of the acute stage of the illness which was iraminent. In acute septic infection every effort should be made to tide over the acute stage, for the prognosis of chronic septicæmia and pyæmia is good. The bæmorrhages had nothing to do with the serum treatment, but were due to blood changes arising out of the acute septic process. The bæmorrhagic condition was treated by chloride of calcium and with fresh milk and fruit; in fact in the manner which yields the best results in scurry and scurvy rickets.

Evelyn-gardens, S.W.

\section{NOTE ON "BLACK-WATER" FEVER"}

BY STANLEY KELLETT SMITH, F.R.C.S. ENG. LATE SURGEON TO THE RHODESIA CONCESSIONS EXPEDITION TO CENTRAL AFRICA.

Is every quarter of the globe where it exists malaria presents certain aspects peculiar to the country. In Central Africa, and indeed throughout the whole of tropical Africa, the phase demanding most attention is the bilious bæmo. globinuric or "black-water" fever. This occurs as a rule only in those who have been for some considerable time in the country and who have suffered from repeated attacks of ordinary fever. It seldom or never seizes the new-comer, but it may appear rapidly in previous residents of a malarious district upon return thereto after absence in a healthy climate. Europeans are the chief sufferers, but cases are not rare among the natives. The clinical features of the disease are those of a severe remittent fever. The cold stage is usually well marked; there may be severe retching and bilious vomiting together with diarrhoa; bleeding from the mucous tracts sometimes occurs. Finally, there are the cardinal symptoms referable to the rapid and extensive destruction of the red blood corpuscles characteristic of the disease-viz., quickly developed jaundice, which is bæmatogenous rather than hepatogenous, and the passage of dark, porter-coloured urine containing oxybæmoglobin, methæmoglobin, and urobilin.

I do not know of the existence of any statistics bearing upon the mortality of this fever. Many patients recover: many die. A good index of its fatality is given by the fear in which "black-water" is beld by the white man. It must always be regarded as a very serious illness. Death may ensue from (1) enormous destruction of the red blood cells, when the symptoms are similar to those of profuse bremorrhage; (2) uræmic poisoning resultant from total suppression of the urine; and (3) interference with some vital cerebral centre owing to blockage of capillaries by masses of malarial parasites or to actual hæmorrhage. As a remote sequence the kidneys may become cirrhotic from the nephritis accompanying and following the disease.

The pathology of "black-water" is as yet an almost virgin field, and the literature thereof is so scant and contradictory as to afford few points of definite argument. A single issue is clouded also by the fact that many observers have reported all cases in which passage of blood in the urine occurred as cases of bilious hæmoglobinuria, although some of these read like descriptions of attacks of ordinary acute nephritis and others have led to a claim of identity between "black-water" fever and the paroxysmal hæmoglobinuria of our own country. This claim is very far from proven, but it is probable that we must come to recognise several distinct conditions, now grouped together under the one head, some of which will support the analogy to paroxysmal hæmoglobinuria, just as we may admit that certain cases of the latter disease have a possible origin in home malaria. An opinion first ventured at the time when "black-water" began to attract serious attention still provides ground for inquiry and speculation. In 1874, 1877, and 1888, Tomaselli published cases occurring in Catania, in people who had suffered from repeated malarial attacks, which presented clinical features

1 Read before the Liverpool Medical Institution on Feb. 17th, 1898. 